\title{
SECONDARY RADIATION MAPPING
}

KEY WORDS: Scatter

Radiation, Dose mapping,

Radiation protection

\section{Ioannis Vlachos}

\section{Ioannis \\ Kandarakis}

\section{Giorgos} Panayiotakis*
Department of Medical Physics, School of Medicine, University of Patras, Patras, 26500 Rion, Patras, Greece.

Department of Medical Instruments Technology, Technological Educational Institution of Athens, Athens, Ag. Spyridonos Street, Egaleo 12210 Athens, Greece.

Department of Medical Physics, School of Medicine, University of Patras, Patras , 26500 Rion, Patras, Greece. *Corresponding Author

Radiation protection for personnel working with X-rays is of vital importance. Several studies have been published regarding the secondary radiation and the shielding requirements to areas that are adjacent to the X-ray units. In this work, secondary radiation in a conventional radiographic room, in terms of dose rate (mSv/hr), as a function of different radiographic exposure factors has been studied. The measurements were performed with a 451P Fluke Biomedical survey meter on a Philips Medio $65 \mathrm{CP}-\mathrm{H}$ X-ray generator with a cylindrical water phantom. It was found that the dose rate from the scatter radiation decreases with distance. An added filtration of $2.0 \mathrm{mmAl}$ at $100 \mathrm{kVp}$ reduced the secondary dose rate further by $21.4 \%$. The results of this study may be of value during exposure of personnel that are not protected by shielding materials.

Highlights

- It was found that the dose rate from the scatter radiation decreases with distance. An added filtration of $2.0 \mathrm{mmAl}$ at $100 \mathrm{kVp}$ reduced the secondary dose rate further by $21.4 \%$.

- The mean secondary X-ray energies for $60,80,100$ and $100 \mathrm{kV}$ with $2 \mathrm{mmAl}$ added, were calculated as 34.41,51.12, 69.03 and $71.29 \mathrm{keV}$ respectively.

- The results of this study are of value during exposure of people such as radiographers, and patients during the use of mobile X-ray units.

\section{INTRODUCTION}

In the last decades, there has been an extended scientific discussion concerning radiation protection and dosimetry in medical X-ray imaging practice ${ }^{(1-5)}$. The presence of different equipment and X-ray practices not only affects the dose of the patients, but the dose of the personnel, as well. There are several studies regarding the necessary shielding requirements in order to protect the occupational and living areas from the X-ray scatter radiation ${ }^{(6-8)}$. Except from shielding calculations, current $\mathrm{X}$-ray practices consider calculation of secondary radiation, in the proximity area to the $\mathrm{X}$-ray tube, to be necessary ${ }^{(1)}$. Such knowledge should be of assistance to technical staff in performing examinations with mobile radiography units, to medical staff in operating mobile fluoroscopic units, or even to escorts. In current literature, several surveys exist, which measure the exposure rate of secondary radiation, from X-ray equipment, either by focusing in $\mathrm{CT}^{(9)}$, or by utilizing Monte Carlo methods ${ }^{(10)}$. The ratio of the scatter over the incident radiation has already been published for a variety of radiation energies ${ }^{(11)}$. Most recently, a paper published by Noto et al (2009) ${ }^{(12)}$, demonstrates the experimental results concerning the fraction of secondary radiation over primary radiation inside an X-ray room. However, although the latter work provides the scatter fractions for a variety of X-ray tube voltages field sizes and angles, it does not provide actual dose rate measurements. Additionally, it does not take into account the variations of X-ray filtration for the same tube voltage.

The aim of this study is the measurement of secondary radiation in a conventional radiographic room, in terms of the dose rate, and the study of the influence of different radiographic exposure factors (tube voltage, tube current, distance), with the field size kept constant. This study can be of importance in optimizing the radiation protection of people and medical personnel, which have to be present in an X-ray room during typical radiography or fluoroscopy procedures. In addition the inclusion of X-ray filtration, as an exposure 162 parameter for $100 \mathrm{kVp}$ tube voltage, can make the presented results applicable to clinical exposure conditions, like coronary angiography, whereby, added filtration and increased tube voltage is utilized for heavy patients.

\section{MATERIALS AND METHODS \\ Experimental Setup}

A conventional radiographic system (Philips Medio $65 \mathrm{CP}-\mathrm{H}$ ) was used. It is equipped with a three phase high voltage generator, a diagnostic X-ray tube with two focal spots, a tube voltage ranging from 40 to $150 \mathrm{kVp}$, a tube current ranging from 5 to $700 \mathrm{~mA}$ and an exposure time ranging from 0.003 to $16 \mathrm{~s}$. The systems (HVL) was measured $3.2 \mathrm{mmAl}$ at $80 \mathrm{kVp}$. The radiography system was installed in the Radiology Department of the Sismanoglio General Hospital of Athens, Greece.

In order to simulate the human body, a cylindrical water phantom with a diameter of $38 \mathrm{~cm}$ and a height of $20 \mathrm{~cm}$ was utilized. The simple symmetrical shape of the phantom diminished the effect of the phantom shape to the measured scattered radiation.

At the bottom, of the cylindrical water phantom a cross mark was sketched so as to focus the tube's light beam to the mark easily and accurately. It was found that deviations in the focus accuracy, up to $5 \mathrm{~cm}$, did not change the resulting dose rate measurements.

The ionization chamber used for measuring the secondary radiation was a calibrated 45lP-DE-SI model of Fluke Biomedical. This model can measure the scattered and radiation leakage around the radiographic tubes ${ }^{(13-15)}$. Such, survey meters have the advantage that they can cover a wide range of photon energies. In this study the irradiation time was kept at $2.5 \mathrm{~s}$ so as to account for the response time of the instrument ${ }^{(14)}$. In order to achieve positioning reproducibility the survey meter was placed on a photographic stand, with 
elevating, rotating mechanisms and wheels.

Although, the $\mathrm{x}$-ray unit is subject to periodical quality controls in order to assure its consistency and reproducibility, it was checked prior to the experiments for consistency and reproducibility and was found to be within acceptable limits ${ }^{(14)}$. The voltage and irradiation time were checked with a noninvasive $\mathrm{x}$-ray test device (Diavolt Universal of PTWFreiburg), while the X-ray output was measured with the Diados E dosimeter of PTW-Freiburg, with the radiation semiconductor detector Diados T60004, which is suitable for tube voltages between 45 to $150 \mathrm{kVp}$. The calibration factors of the T60004 detector are selectable for different x-ray filtration and the detection system does not require air density correction with a radioactive check device or measurement of air pressure and temperature ${ }^{(16-17)}$.

The phantom was placed on the radiographic table and irradiated at a stable field size of $40 \times 40 \mathrm{~cm}^{2}$, and at a stable distance between the tube focal spot and the phantom at 1.0 $\mathrm{m}$. The x-ray field that was utilized was $40 \mathrm{x} 40 \mathrm{~cm}^{2}$, so as to completely cover the cylindrical phantom of $38 \mathrm{~cm}$ diameter, and to avoid angular dependence of the results, due to the different self absorption. In addition, the large field size will provide more conservative results and thus provide a worst case scenario which may be of importance in radiation protection issues. The survey meter was placed at a height of $15 \mathrm{~cm}$ related to the phantom bottom, with its measuring surface viewing the phantom, as well as, the scattered radiation coming from the unit table and room floor (figure 1 ).

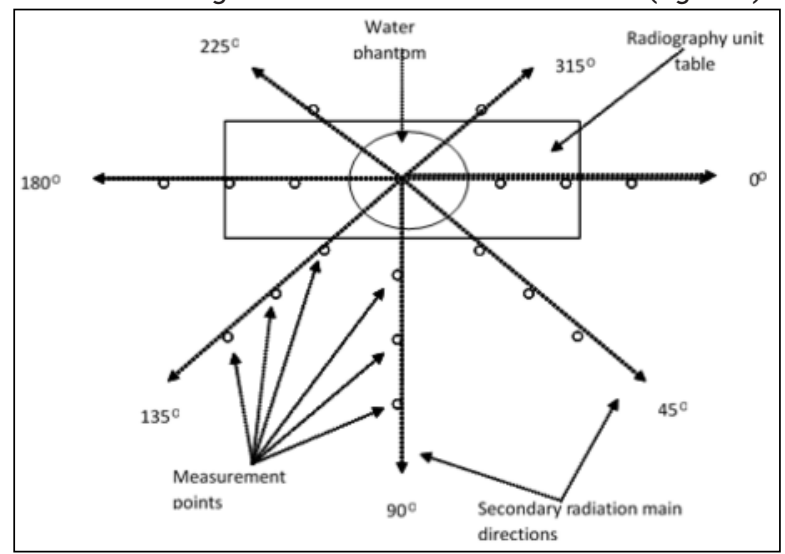

Figure 1. Secondary Radiation Measurement Positions In The Radiographic Room

The scatter radiation was measured at different scattering angles around the water phantom $\left(0^{\circ}\right.$ to $360^{\circ}$, with a step of $45^{\circ}$ ) and at distances of $1.0,1.5$ and $2.0 \mathrm{~m}$ respectively from the center of the phantom, for different exposure parameters. The height of the survey meter in respect to the bottom of the phantom was kept stable.

\section{Experimental Methodology}

The experimental procedure was divided into three parts of measurements. In the first part, the dose rate inside the room was measured for increasing values of the tube current, 10, 25 and $50 \mathrm{~mA}$ keeping the rest of the exposure factors stable: 100 $\mathrm{kVp}, 2.5 \mathrm{~s}$.

The primary beam filtration was inherent. In the second part, the measurements were repeated with an additional filtration of $2 \mathrm{mmAl}$ at the tube voltage of $100 \mathrm{kVp}$ in order to simulate higher filtered X-ray tubes utilized mainly in interventional radiology procedures for heavy patients.

Finally, the dose rate was measured for increasing the tube voltage values $(60,80$ and $100 \mathrm{kVp})$, by keeping the rest of exposure factors stable at $2.5 \mathrm{~s}$ and $25 \mathrm{~mA}$. In this case, the primary beam filtration, was again the inherent.

\section{Setup Errors Study}

2.2.1.1 Study of reading errors: The scale reading error of the survey meter was not greater than $0.05 \mathrm{mSv} / \mathrm{hr}$, when the meter was turned to the lower counting range $(0-5 \mathrm{mSv} / \mathrm{hr})$, and $0.5 \mathrm{mSv} / \mathrm{hr}$, when turned to the higher range (5-50 $\mathrm{mSv} / \mathrm{hr}$ ).

2.2.1.2 Study of the focal spot to the phantom distance: Tests showed that a setup difference of 1 to $2 \mathrm{~cm}$ in the focal spot to phantom distance had no significant result on the measurements. For distance differences greater than $(1 \pm 0.02) \mathrm{m}$ from the phantom, the measured dose rate difference was found to be approximately $0.8 \mathrm{mSv} / \mathrm{hr}$, for tube voltages of 80 and $100 \mathrm{kVp}$. For the tube voltage of $60 \mathrm{kVp}$ the relative deviations were greater. During our measurements, the experimental error of the focal spot to phantom distance was never greater than $0.1 \mathrm{~cm}$.

2.2.1.3 Study of tube light beam focus at the centre of phantom: Tests showed that an error of 1 to $5 \mathrm{~cm}$ of the tube light beam focus did not affect the measured secondary radiation values. But, for errors in positioning greater than 5 $\mathrm{cm}$, the deviation in the dose rate measurements was 0.5 $\mathrm{mSv} / \mathrm{hr}$, at $1 \mathrm{~m}$ from the phantom. In all experimental cases, true error of the light beam focus was never greater than $1 \mathrm{~cm}$.

2.2.1.4 Study of the survey meter placement: The error of the survey meter placement towards the phantom was never greater than $1 \mathrm{~cm}$ and the error of placement concerning the angle was less than 1 degree. Tests revealed that the angular errors did not change the measurements much, but the absolute verticality of the survey meter towards the center of the phantom did. So, a system of a special plastic stand, the tubes meter, an outer meter and a protractor meter, was used for the exact placement of the survey meter. In all measuring cases, the experimental procedure was the following: a) the focal spot to the phantom distance was first measured with the tubes and the outer meter, b) the distance from the center of the tubes light spot to the measuring point in the room was measured, $c$ ) the base of the stand was placed in the room, d) the plastic protractor was placed on the base stand, and e) the survey meter was placed on the protractor.

2.2.1.5 Study of background and leakage radiation measurements: At every new placement of the survey meter in the room, the background and the leakage radiation levels were measured. Otherwise, all dose rate measurements would include unknown and unpredictable placement errors. The background measurements had values compared with the scale reading error, of the lower counting range of the survey meter, mentioned in 2.3.1. Leakage radiation was measured at a target angle of $90^{\circ}$, at a distance of $1 \mathrm{~m}$ from the phantom and for exposure factors of $100 \mathrm{kV}, 50 \mathrm{~mA}$ and $2.5 \mathrm{~s}$ and was also found comparable to the scale reading error, of the lower counting range of the survey meter.

\section{Energy Distribution Of Scatter Radiation}

An Amptek XR-100 CdTe spectrometer was positioned at right angles to the phantom at a distance of $50 \mathrm{~cm}$. The spectrometer was equipped with a collimator having a diameter of $0.2 \mathrm{~mm}$. The response of the spectrometer for various energies in terms of energy per bin and detector quantum efficiency per energy value was known through calibration in various radiation energies ${ }^{(18)}$. The correction of the spectrometer with respect to the energy per X-ray bin was equal to $(1 / 5.89) \mathrm{KeV}$.

In addition the quantum efficiency response (QE) of the CdTe obtained from the manufacturer data sheet was equal to )(09959.1EfEQE $++=$, where $\mathrm{E}$ is the $\mathrm{X}$-ray energy and $\mathrm{f}(\mathrm{E})$ is the measured number of photons per $\mathrm{mm}^{2}$. The X-ray spectra measured comprised X-ray tube voltages of $60 \mathrm{kVp}, 80 \mathrm{kVp}$, $100 \mathrm{kVp}$ and $100 \mathrm{kVp}$ with an additional $2 \mathrm{mmAl}$ filtration. The $\mathrm{X}$-ray tube load was at $45 \mathrm{mAs}$. 


\section{RESULTS AND DISCUSSION}

\section{Quality Control Results Of The Radiographic Tube}

The accuracy of the X-ray tube voltage was $2.7 \%$, and its reproducibility was $0.05 \%$. The measurements were performed with the PTW-Freiburg T43014, Diavolt Universal $\mathrm{kVp}$-Dose-time meter placed at a distance of $\mathrm{lm}$ from the focal spot on the upper surface of the cylindrical phantom. During these quality tests procedures no additional primary beam filtration was used. The tube voltage deviation from the theoretical data was taken into account during the measurements. When exposure time was considered both accuracy and reproducibility were below $0.1 \%$.

The total filtration of the primary beam is an essential parameter concerning the exposure, the absorbed dose, the image quality and scattered radiation. The total filtration or quality of the radiation produced was calculated by measuring the Half Value Layer (HVL). In routine quality assurance tests, the HVL is calculated at the tube voltage of 80 $\mathrm{kVp}$ and must be higher than $2.5 \mathrm{mmAl}^{(15)}$. The HVL calculated was $3.2 \mathrm{mmAl}$ at $80 \mathrm{kVp}$. In this study, most of the measurements used a tube voltage of $100 \mathrm{kV}$, but the HVL was calculated in all used cases, as seen in table 1. Furthermore, when the additional filtration of $2.0 \mathrm{mmAl}$ was added, the corresponding $\mathrm{HVL}$ at $100 \mathrm{kVp}$ was found to be equal to 4.6 mmAl.

\begin{tabular}{|c|c|}
\hline \multicolumn{2}{|c|}{$\begin{array}{l}\text { Table } 1 \text {. The X-ray beam Half Value Layer (HVL) for } \\
\text { different X-ray tube voltages. }\end{array}$} \\
\hline Tube voltage $(\mathrm{kVp})$ & Calculated HVL (mmAl) \\
\hline 60 & 2.7 \\
\hline 80 & 3.2 \\
\hline 100 & 3.7 \\
\hline $100(2.0 \mathrm{~mm} \mathrm{Al}$ added $)$ & 4.6 \\
\hline
\end{tabular}

The X-ray tube output was measured in all three tube voltages $(60,80$ and $100 \mathrm{kVp})$. The dose detector was placed on the upper surface of the phantom at $1 \mathrm{~m}$ from the focal spot and the exposure field had dimensions of $40 \times 40 \mathrm{~cm}^{2}$ in coincidence with the detectors $\square 60004$ window. The results are presented in Tables 2.1 to 2.3. As it can be observed, for the tube voltage of $100 \mathrm{kVp}$ and with an additional filtration of $2.0 \mathrm{mmAl}$, the mean X-ray output was found to be equal in average to 0.099 $\mathrm{mGy} / \mathrm{mAs}$. The corresponding value without the additional filtration was equal to $0.146 \mathrm{mGy} / \mathrm{mAs}$.

\section{Dose Rate Results}

In the Appendix, the measured dose rate results for various angles, tube voltages and X-ray filtration are demonstrated. In Table $A 1$ the dose rate, for angles of $0^{\circ}, 45^{\circ}, 90^{\circ}, 135^{\circ}$ and $180^{\circ}$, for increasing tube current, at $100 \mathrm{kVp}$, is demonstrated. The measurements were performed without the additional filtration. As expected, the dose rate decrease per distance is a function of the distance. That is from $1.0 \mathrm{~m}$ to $1.5 \mathrm{~m}$ the dose rate decreases $49.2 \%$ on average for each case, while for distances between $1.5 \mathrm{~m}$ and $2.0 \mathrm{~m}$ the dose rate decreases $45 \%$ on average for each case. In addition, the dose rate was found to be roughly proportional to the tube current. In Table A2, the dose rate, for angles $0,45,90,135$ and 180, for increasing the tube current and extra added filtration of 2.0 $\mathrm{mmAl}$, at $100 \mathrm{kVp}$, is demonstrated. The decrease of the dose rate as a function of distance is similar as shown in Table Al. The corresponding results of Table A2 show that the relative mean decrease of the dose rate of scattered radiation, with respect to the results presented in Table $A 1$, is estimated to be almost $15.6 \%$ (from $9.7 \%$ to $21.4 \%$ ). This variance was expected, as the extra filtration of the primary beam changes the penetrating ability of radiation in the phantom, as well as and finally the resulting scattered percentage, with the corresponding function of the tube current and distance from the phantom. In Table $\mathrm{A} 3$ the dose rate for the $\mathrm{X}$-ray tube voltages $60 \mathrm{kVp}, 80 \mathrm{kVp}$ and $100 \mathrm{kVp}$, with irradiation conditions of $25 \mathrm{~mA}$ and $2.5 \mathrm{~s}$ is demonstrated. No additional filtration is added. From Table A3 it can be seen that an increase of the tube voltage from 60 to $80 \mathrm{kV}$ over triples the dose rate for the same distances. Additionally, an increase of the tube voltage from 80 to $100 \mathrm{kVp}$ approximately doubles the dose rate.

\begin{tabular}{|c|c|c|c|c|c|c|c|c|}
\hline \multicolumn{9}{|c|}{$\begin{array}{l}\text { Table Al: Dose rate of secondary radiation, tube } \\
\text { voltage of } 100 \mathrm{kVp} \text { and } 2.5 \mathrm{~s} \text { exposure time. }\end{array}$} \\
\hline \multicolumn{2}{|c|}{$\begin{array}{l}\text { Angle of scattered } \\
\text { radiation (degrees) }\end{array}$} & $0^{\circ}$ & $45^{\circ}$ & $90^{\circ}$ & $135^{\circ}$ & $180^{\circ}$ & $225^{\circ}$ & $315^{\circ}$ \\
\hline \begin{tabular}{|l|} 
Distanc \\
e from \\
the \\
phanto \\
$\mathrm{m}(\mathrm{m})$
\end{tabular} & $\begin{array}{l}\text { Tube } \\
\text { Current } \\
(\mathrm{mA})\end{array}$ & \multicolumn{7}{|c|}{$\begin{array}{l}\text { Secondary radiation dose rate } \\
(\mathrm{mSv} / \mathrm{hr})\end{array}$} \\
\hline 1.0 & 10 & 7.0 & 7.0 & 6.5 & 7.0 & 6.5 & 6.5 & 8.0 \\
\hline 1.0 & 25 & 19.0 & 19.0 & 18.5 & 19.5 & 18.5 & 18.5 & 22.0 \\
\hline \begin{tabular}{|l|}
1.0 \\
\end{tabular} & 50 & 33.0 & 37.5 & 36.0 & 38.0 & 36.5 & 36.5 & 44.0 \\
\hline 1.5 & 10 & 3.3 & 3.4 & 3.6 & 3.4 & 3.3 & - & - \\
\hline 1.5 & 25 & 8.0 & 8.0 & 8.5 & 8.0 & 8.0 & - & - \\
\hline 1.5 & 50 & 17.0 & 17.5 & 18.5 & 17.5 & 17.5 & - & - \\
\hline 2.0 & 10 & 2.0 & 1.9 & 2.0 & 1.9 & 2.0 & - & - \\
\hline \begin{tabular}{|l|}
2.0 \\
\end{tabular} & 25 & 4.5 & 4.9 & \begin{tabular}{|l|}
4.5 \\
\end{tabular} & 4.9 & 4.9 & - & - \\
\hline 2.0 & 50 & 9.5 & 9.5 & 10.0 & 9.5 & 9.5 & - & - \\
\hline
\end{tabular}

Table A2: Dose rate in $\mathrm{mSv} / \mathrm{hr}$, with the additional filter of $2 \mathrm{mmAl}$ at $100 \mathrm{kVp}$ tube voltage and $2.5 \mathrm{~s}$ exposure time.

\begin{tabular}{|l|l|l|l|l|l|l|l|l|l|}
\hline $\begin{array}{l}\text { Angle of scattered } \\
\text { radiation (degrees) }\end{array}$ & $0^{\circ}$ & $45^{\circ}$ & $90^{\circ}$ & $135^{\circ}$ & $180^{\circ}$ & $225^{\circ}$ & $315^{\circ}$ \\
\hline $\begin{array}{l}\text { Distance } \\
\text { from the } \\
\text { phantom (m) }\end{array}$ & $\begin{array}{l}\text { Tube } \\
\text { Current } \\
(\mathrm{mA})\end{array}$ & \multicolumn{7}{|l|}{$\begin{array}{l}\text { Secondary radiation dose rate } \\
(\mathrm{mSv} / \mathrm{hr})\end{array}$} \\
\hline 1.0 & 10 & 5.5 & 5.5 & 5.5 & 6.0 & 5.5 & 5.5 & 6.5 \\
\hline 1.0 & 25 & 15.5 & 15.5 & 15.0 & 16.0 & 15.0 & 15.5 & 18.0 \\
\hline 1.0 & 50 & 33.5 & 33.0 & 32.5 & 33.5 & 32.5 & 33.0 & 36.0 \\
\hline 1.5 & 10 & 2.8 & 2.8 & 3.0 & 2.7 & 2.9 & - & - \\
\hline 1.5 & 25 & 6.5 & 6.5 & 7.0 & 6.5 & 7.0 & - & - \\
\hline 1.5 & 50 & 14.0 & 14.5 & 15.0 & 14.5 & 14.5 & - & - \\
\hline 2.0 & 10 & 1.7 & 1.7 & 1.7 & 1.7 & 1.7 & - & - \\
\hline 2.0 & 25 & 4.3 & 4.1 & 4.3 & 4.2 & 4.2 & - & - \\
\hline 2.0 & 50 & 8.0 & 8.0 & 8.0 & 8.0 & 8.0 & - & - \\
\hline
\end{tabular}

Table A3: Dose rate in $\mathrm{mSv} / \mathrm{hr}$, with no added filtration for different tube voltages, $25 \mathrm{~mA}$ current value and 2.5 s exposure time.

\begin{tabular}{|l|l|l|l|l|l|l|l|l|l|l|}
\hline $\begin{array}{l}\text { Angle of scattered } \\
\text { radiation (degrees) }\end{array}$ & $0^{\circ}$ & $45^{\circ}$ & $90^{\circ}$ & $135^{\circ}$ & $180^{\circ}$ & $225^{\circ}$ & $315^{\circ}$ \\
\hline $\begin{array}{l}\text { Distance } \\
\text { from the } \\
\text { phantom (m) }\end{array}$ & $\begin{array}{l}\text { Tube } \\
\text { Voltage } \\
(\mathrm{kVp})\end{array}$ & \multicolumn{2}{|l|}{$\begin{array}{l}\text { Secondary radiation dose rate } \\
(\mathrm{mSv} / \mathrm{hr})\end{array}$} \\
\hline 1.0 & 100 & 19.0 & 19.0 & 18.5 & 19.5 & 18.5 & 18.5 & 22.0 \\
\hline 1.5 & 100 & 8.0 & 8.0 & 8.5 & 8.0 & 8.0 & - & - \\
\hline 2.0 & 100 & 4.5 & 4.9 & 4.5 & 4.9 & 4.9 & - & - \\
\hline 1.0 & 80 & 8.5 & 8.0 & 8.5 & 8.0 & 8.0 & 8.5 & 9.5 \\
\hline 1.5 & 80 & 4.0 & 3.8 & 4.1 & 3.9 & 3.9 & - & - \\
\hline 2.0 & 80 & 2.3 & 2.3 & 2.5 & 2.3 & 2.3 & - & - \\
\hline 1.0 & 60 & 2.5 & 2.5 & 2.6 & 2.4 & 2.4 & 2.5 & 2.8 \\
\hline 1.5 & 60 & 1.1 & 1.1 & 1.2 & 1.1 & 1.1 & - & - \\
\hline 2.0 & 60 & 0.7 & 0.7 & 0.7 & 0.6 & 0.6 & - & - \\
\hline
\end{tabular}

Table A4: Secondary dose rate / unit output for different tube voltage at $1.5 \mathrm{~m}$, at $90^{\circ}$ angle.

\begin{tabular}{|l|l|l|l|}
\hline $\begin{array}{l}\text { Tube voltage } \\
(\mathrm{kVp})\end{array}$ & $\begin{array}{l}\text { X-ray } \\
\text { output } \\
(\mathrm{mGy} / \\
\mathrm{mAs})\end{array}$ & $\begin{array}{l}\text { Scatter } \\
\text { radiation dose } \\
\text { rate at } 1.5 \mathrm{~m}, \text { at } \\
90^{\circ} \text { angle } \\
(\mathrm{mSv} / \mathrm{hr})\end{array}$ & $\begin{array}{l}\text { Dose rate/ Unit } \\
\text { output } \\
(\mathrm{mSv} / \mathrm{hr}) /(\mathrm{mGy} / \mathrm{m} \\
\text { As })\end{array}$ \\
\hline 60 & 0.04 & 1.2 & 30.00 \\
\hline 80 & 0.09 & 4.1 & 45.55 \\
\hline 100 & 0.15 & 8.5 & 56.70 \\
\hline $\begin{array}{l}100(2.0 \mathrm{mmAl} \\
\text { added })\end{array}$ & 0.10 & $\begin{array}{l}7.0(25 \mathrm{~mA} \\
\text { current value })\end{array}$ & 70.00 \\
\hline
\end{tabular}


Furthermore, as it can be seen from Figure 2 the measured values at angles from $225^{\circ}$ to $315^{\circ}$ are relatively increased. This is because the radiographic system is placed too close to the wall of the room (Figure 1) and the backscattered radiation from the wall and the tube arm contributed to our measurements. The phenomenon was more intense in the cases of $50 \mathrm{~mA}$ tube current and of $100 \mathrm{kVp}$ tube voltage. Finally, the phenomenon seemed to be less intense when the additional $2.0 \mathrm{mmAl}$ filter was used. A point worth commenting on, is that for the same $\mathrm{kVp}$ and $\mathrm{mA}$ combinations the measured dose rates at values of $0^{\circ}$ to $180^{\circ}$ are comparable. This occurs because of the cylindrical symmetry of the phantom used in our measurements. A different phantom in shape could alter the X-ray angle distribution ${ }^{(12)}$.

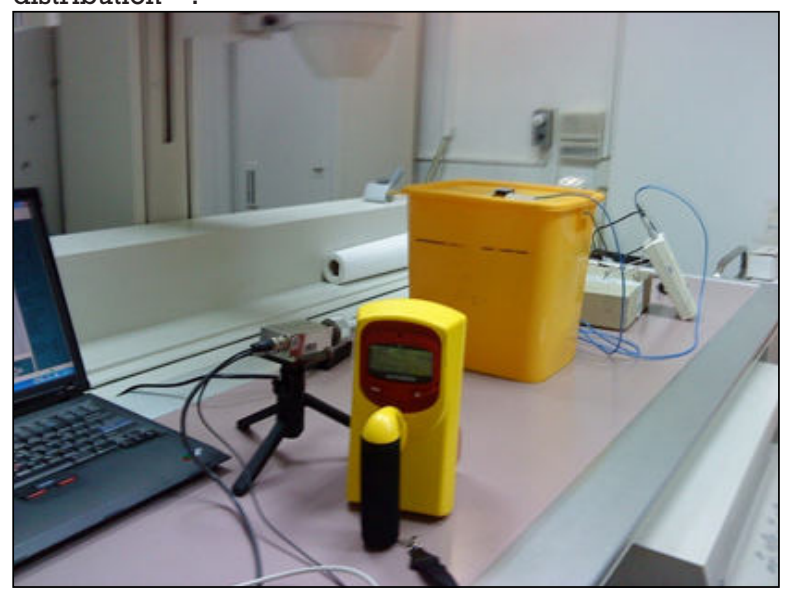

Figure 2. Energy Distribution Of Scatter Radiation Using Spectrometer.

The experimental values are higher, from what could be expected from theoretical calculations because of the walls, table and floor scatter radiation, the non point dimensions of the X-ray source and the effective volume of our radiation survey. However, this result can be of value in estimating radiation doses in staff and people present during X-ray examinations.

Figures 3 , shows the linearity of the measured results in function with the tube current, at a $\mathrm{lm}$ distance from the phantom, at the angle of 90 degrees.

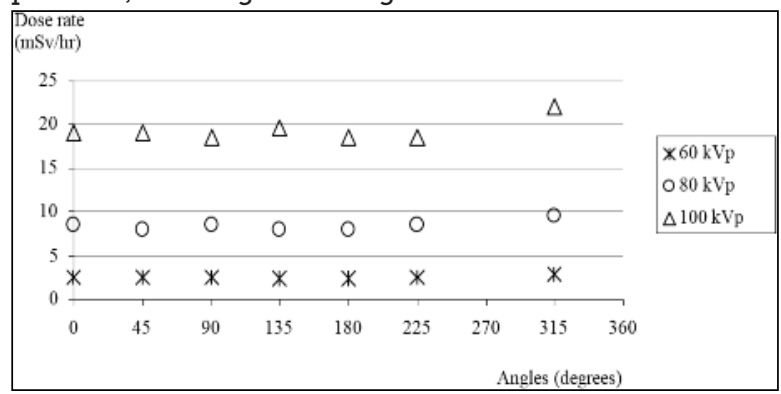

Figure 3: The Cylindrical Water Phantom And The Different Target Angles.

In table $\mathrm{A} 4$ the scatter radiation dose rate per $\mathrm{X}$-ray output (SDRO) in different exposure conditions is demonstrated. It can be observed that SDRO increases with X-ray tube voltage. In addition an external added filtration, corresponding to an increase of the mean energy of the incident X-ray spectrum at $100 \mathrm{kVp}$, increases the SDRO further. The results of Table A4 may be of value for exposure parameters optimization with regard to patient dose, personnel and public radiation protection. Furthermore table A4 is of value for assessing the scatter radiation in clinical conditions provided that the $\mathrm{X}$-ray tube output is measured and the corresponding HVL values are similar to the ones presented in this study (Table 1).
${ }^{\circ}$ Finally in Figure 4 the measured X-ray spectra of the secondary radiation are presented. The mean secondary $\mathrm{X}$ ray energies for $60 \mathrm{kV}, 80 \mathrm{kV}, 100 \mathrm{kV}$ and $100 \mathrm{kV}$ with $2 \mathrm{mmAl}$ added, were calculated as $34.41 \mathrm{KeV}, 51.12 \mathrm{KeV}, 69.03 \mathrm{KeV}$ and $71.29 \mathrm{keV}$ respectively. The measured scatter distribution is less sensitive to the large scatter X-rays than the survey meter due to the narrow beam geometry utilized from CdTe. In the same figure, in $60 \mathrm{kV}$ the photons are very less, less than 2.000 photons $/ \mathrm{mm}^{2}$ and the high voltage is under than $50 \mathrm{keV}$. For the $80 \mathrm{kV}$ the energy destruction is better, because the photons $/ \mathrm{mm}^{2}$ is more and the same for the keV. Energy resolution as a function of photon energy was determined using the radiations listed above. Up to $90 \mathrm{kev}$ this relationship can be adequately represented by $\Delta \mathrm{E} / \mathrm{E}=1 \cdot 12 \mathrm{E}^{-0.48}(\Delta \mathrm{E}$ is the full width at half-maximum of a photopeak, and $E$ is the photon energy in kev). Above $90 \mathrm{keV}$ determination of energy resolution is complicated by the non-linear response of the crystal. Since the magnitude of photon fluence above $90 \mathrm{keV}$ was small compared to that at lower energies, exact determination of energy resolution above $90 \mathrm{keV}$ was unnecessary.

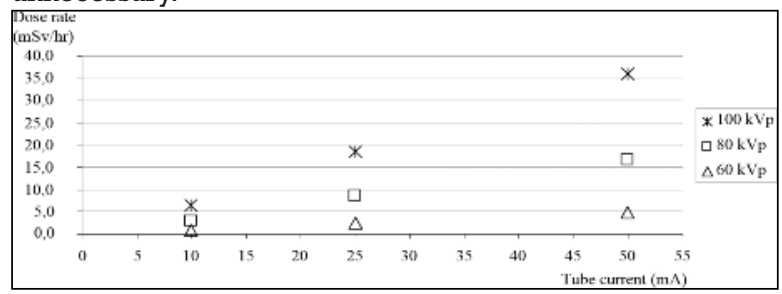

Figure 4: Secondary Dose Rate For Various Angle And 3 Tube Voltage (25 mA, $2.5 \mathrm{~s}$, no additional filtration).

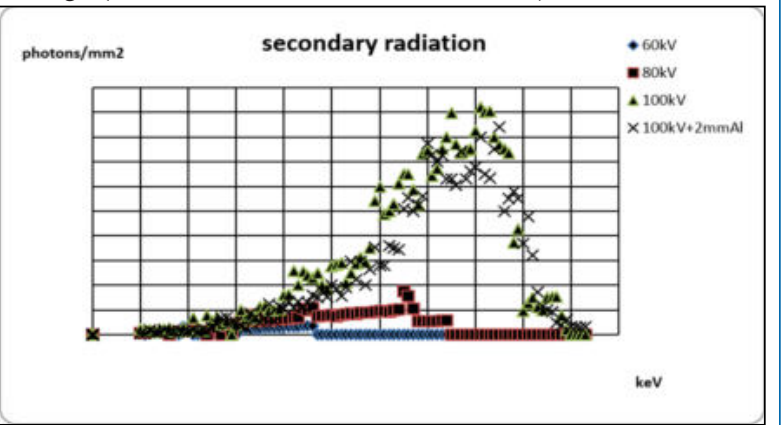

Figure 5: Secondary radiation energy distribution for $90^{\circ}$ angle for a different X-ray tube voltages measured at $50 \mathrm{~cm}$ from the phantom at $45 \mathrm{mAs}$.

Table 2.1. X-ray tube output measurements at $1 \mathrm{~m}$ tube voltage of $100 \mathrm{kVp}$ and $2.5 \mathrm{~s}$ exposure time for various current values, with no additional filtration.

\begin{tabular}{|l|l|l|}
\hline Tube current & Air KERMA & Output \\
\hline$(\mathrm{mA})$ & $(\mathrm{mGy})$ & $(\mathrm{mGy} / \mathrm{mAs})$ \\
\hline 10 & 3.529 & 0.141 \\
\hline 25 & 9.203 & 0.147 \\
\hline 50 & 18.600 & 0.149 \\
\hline
\end{tabular}

Table 2.2. X-ray tube output measurements at $1 \mathrm{~m}$ tube voltage of $100 \mathrm{kVp}$ and $2.5 \mathrm{~s}$ exposure time for various carrent values, and with additional filtration of $\mathbf{2 . 0}$ mmAl.

\begin{tabular}{|l|l|l|}
\hline Tube current & Air KERMA & Output \\
\hline$(\mathrm{mA})$ & $(\mathrm{mGy})$ & $(\mathrm{mGy} / \mathrm{mAs})$ \\
\hline 10 & 2.435 & 0.097 \\
\hline 25 & 6.264 & 0.100 \\
\hline 50 & 12.580 & 0.101 \\
\hline
\end{tabular}

Table 2.3. X-ray tube output measurements at $1 \mathrm{~m}$ in various tube voltage values, $25 \mathrm{~mA}$ current value and $2.5 \mathrm{~s}$ exposure time, with no additional filtration.

\begin{tabular}{|l|l|l|}
\hline Tube Voltage & Air KERMA & Output \\
\hline$(\mathrm{kVp})$ & $(\mathrm{mGy})$ & $(\mathrm{mGy} / \mathrm{mAs})$ \\
\hline 60 & 2.718 & 0.043 \\
\hline
\end{tabular}




\begin{tabular}{|l|l|l|}
\hline 80 & 5.600 & 0.090 \\
\hline 100 & 9.203 & 0.147 \\
\hline
\end{tabular}

\section{CONCLUSIONS}

Results showed that the scattered radiation was uniform in the space around the water cylindrical phantom, with some exceptions which are attributed to the presence of the examination table, the vertical bucky and the system support of the tube. Furthermore, it was found that the dose rate decrease in air is larger than $40 \%$, for every half meter away from the phantom, while its angular distribution remained almost stable given the symmetry of the phantom. The added filtration of $2.0 \mathrm{mmAl}$, further reduced the scattered dose rate by $21.4 \%$, because of the related decrease in the X-ray tube output. Finally, if our results are normalized per tube output, i.e. $(\mathrm{mSv} / \mathrm{hr}) /(\mathrm{mGy} / \mathrm{mAs})$, they are of value in estimating the scatter radiation dose rate from the $\mathrm{X}$-ray tube output measurements. The results of this study are of value during exposure of people not protected by shielding materials such as radiographers, and patients during the use of mobile X-ray units, since it has demonstrated that the choice of the tube voltage and filtration affects of the dose rate from the scatter radiation.

\section{APPENDIX}

In the following Tables, $\mathrm{Al}$ to $\mathrm{A} 4$, the scatter radiation dose measurements are demonstrated.

\section{REFERENCES}

1. International Atomic Energy Agency (IAEA), 2004. Optimization of the radiological protection of patients undergoing radiography, fluoroscopy and computed tomography. IAEA Safety Standards Series, IAEA-TECDOC-1423, http://www-ns.iaea.org/standards/,December.

2. IAEA Safety Reports Series No 39, 2006. Applying Radiation Safety Standards in Diagnostic radiology and Interventional Procedures Using X-rays. International Atomic Energy Agency (IAEA), STI/PUB/1206, ISBN 92-0111004-9,Vienna.

3. European Commission, 2008. European Guidance on Estimating Population Doses from Medical X-ray Procedures. Radiation Protection No 154 Directorate-General for Energy and Transport, Directorate H-Nuclear Energy,Unit H.4-Radiation Protection.

4. Poludniowski GG, 2007. Calculation of $x$-ray spectra emerging from an $x$-ray tube. Part II. X-ray production and filtration in x-ray targets. Med Phys. 34, 2175-2186.

5. McCullough EC, Cameron JR, 1970. Exposure rates from diagnostic X-ray units. Br.J.Radiol. 43,448-451.

6. Simpkin DJ, and Dixon R.L, 1998. Secondary shielding barriers for diagnostic X-rays facilities scatter and leakage revisited. Health Phys. 74, 350-365.

7. Tsalafoutas I.A, Yakoumakis E, and Sandilos P, 2003. A model for calculating shielding requirements in diagnostic X-ray facilities. Br.J. Radiol.76, 731-737.

8. Noto K, Koshida K, 2003. Estimation of $90^{\circ}$ scattering coefficient in the shielding calculation of diagnostic x-ray equipment. Proceedings of the eleventh EGS4 users' meeting in Japan, KEK proceedings. 15, p. 107-113.

9. Mellenberg DE, SatoY,Thompson BH,Warnock NG, 1999. Personnel exposure rates during simulated Biopsies with a real-time Ct Scanner. Acad. Radiol. 6, 687-690.

10. Mc Vey G, Phil D, Weatherburn H, 2004. A study of scatter in diagnostic x-ray rooms. Br.J.Radiol. 77,28-38.

11. National Council on Radiation Protection and Measurements. Structural Shielding design and evaluation for medical use of X-rays and gamma rays of energies up to $10 \mathrm{MeV}$.NCRP Report No. 49,2009. Bethesda:National Council on Radiation Protection and Measurements.

12. Noto K, Koshida K, Iida H, Yamamoto T, Kobayashi I, Kawabata C, 2009 Investigation of scatter fractions for estimating leakage dose in medical X-ray imaging facilities. Radiol. Phys.Technol., 2, 138-144.

13. Health Physics Society, Specialists in Radiation Safety. Instrumentation and measurements - Surveys and measurements, http://www.hps.org/ publicinformation/ (last accessed May) 2013.

14. Fluke Biomedical model 451P-DE-SI manual, http://www.flukebiomedical. com/Biomedical/ usen/Support/Manuals/ default.htm (last accessed May) 2013.

15. Economides S, Hourdakis CJ, Kalivas N, Kalathatki M, Simantirakis G, Tritakis P, Manousaridis G, Vogiatzi S, Kipouros P, Boziari A, Kamenopoulou V, 2007. Performance of medical radiographic X-ray systems in Greece for the time period 1998-2004. Physica Medica. 23, 107-114.

16. PTW, http://www.ptw.de/diados_e_diagnostic_dosemeter.html. (last accessed May) 2013.

17. Tsalafoutas IA,2006. Excessive leakage radiation measured on two mobileXray units due to the methodology used by the manufacturer to calculate and specify the required tube shielding. Br.J.Radiol.79, 162-164.

18. Michail C.M., Spyropoulou V.A., Fountos G.P., Kalyvas N.I., Valais I.G. Kandarakis I.S. and Panayiotakis G.S, 2011. Experimental and Theoretical Evaluation of a High Resolution CMOS Based Detector Under X-ray Imaging Conditions, IEEETNS 58,314-322. 